\title{
REALIZATION OF GENOTYPIC VARIABILITY IN TOMATO (Licopersicon esculentum Mill.) IN THE GREENHOUSE CONDITIONS DURING PERIODIC SELECTION
}

\author{
L.A. Tarutina ${ }^{1}$, L.A. Mishin ${ }^{2}$, V.N. Kavtsevich ${ }^{3}$ L.V. Khotyleva ${ }^{1}$ \\ ${ }^{1}$ Institute of Genetics and Cytology, National Academy of Sciences of Belarus, 27, ul. Akademicheskaya, Minsk, 220072 Belarus \\ e-mail:L.Tarutina@igc.bas-net.by,L.Khotyleva@igc.bas-net.by \\ ${ }^{2}$ Institute of Plant Growing, National Academy of Sciences of Belarus, 127, ul. Mayakovskogo, Minsk, 220000 Belarus \\ e-mail: LEO123@tut.by \\ ${ }^{3}$ Maxim Tank Belarusian State Pedagogical University, 1, prosp. Nezavisimosti, Minsk, 220000 Belarus
}

Received December 21, 2010

$\mathrm{Su} \mathrm{m}$ m a r y

The creation of heterotic hybrids by means of conjunction of necessary alleles as result of recombination - is one of the most promising ways of adaptive selection. The raising of frequency of recombination in tomato as self-pollinator, therefore, has large value. In the present article the authors study a model efficiency of intra- and interpopulation breeding in connection with degree of genetic variability in Licopersicon esculentum Mill. tomato lines for protected soil. The Start (24-E $\times 12-B)$ and Nadezhda (24-E $\times$ 21-17) indeterminant hybrids and their parents forms were used as initial material. The 24-E and 21-17 parental forms, obtained by 2-year inbreeding from the Vezha local variety and the Matra Holland variety, respectively, have high combination ability on main components of productivity. The 12-B form from collection of N.I. Vavilov All-Russian Scientific Research Institute of Plant Growing, St. Petersburg has complex resistance to cladosporium and TMV. The crossing during obtaining $F_{1}$ hybrids were made by hand. The results, obtained on $F_{1}$ hybrids of Start and Nadezhda forms, were shown that used optimal schemes for periodical breeding with minimal inbreeding and regular hybridization increase the practical frequency of combination of necessary genes, influenced on productivity and resistance to diseases, and may be used for improvement of parental forms and rising of heterosis effect in hybrids. The isolated in two cycles periodical selection the $F_{1}$ hybrids excelled the initial hybrids in productivity of 6-10\% and kept the complex resistance to TMV and cladosporium, that suggests about an efficiency of present models in tomato breeding for heterosis.

Keywords: heterosis, tomato, green house, recurrent selection.

Creation of heterotic hybrids is a promising approach currently used in the adaptive breeding of various crops including tomato (1). In the literature data, mechanisms of heterosis are primarily associated with genetically determined additive effects and domination, and in some cases - overdominance and epistasis (2-5). In this regard, breeding program result in viable forms with balanced genetic systems and broad adaptivity if the initial population has desirable alleles that can be recombined in subsequent generations to provide a desired result.

Increasing the frequency of recombination is especially important in tomato, a self-pollinator with low probability of crosspollination. The frequency of recombination can be significantly improved by re-hybridization of selected genotypes. This cyclical scheme of breeding is called periodic selection, when each cycle includes selection, the assessment of best individuals and subsequent hybridization of them (6-8). Periodic selection causes small repeated changes in the frequency of genes in population as a result of selection pressure and it is considered as effective if hybrids derived from improved secondary populations exceed hybrids of the initial population. Periodic selection uses intra- and interpopulational methods (9) that, in the first case, improve populations themselves, and in the second - population hybrids.

In tomatoes, the first cycle of reciprocal periodic selection was conducted on the intervarietal hybrid Talalikhin $186 \times$ Bison 639 (10). In this case, the developed modification of this method was highly efficient on tomato for open ground with sufficient pool of genetic diversity allowing the a second cycle of selection in improved parental varieties-populations.

The purpose of this work was studying the effects of intra- and interpopulation models of periodic selection depending on the amount of genetic variation in populations, as well as establishing the optimal model for improving a greenhouse tomato by heterosis breeding of the source material.

Technique. A source material was indeterminate hybrids of tomato Start (24-E $\times 12-\mathrm{B})$, Nadezhda $(24-\mathrm{E} \times 21-17)$ and their parental forms. Parental forms 24-E and 21-17 were derived through a 2-year inbreeding of, respectively, a local variety Vezha and Dutch variety Matra, which have high combining ability for major productivity components. The form 12-B from the World collection of N.I. Vavilov Research Institute of Plant Industry (VIR) has a broad-spectrum resistance to TMV and Cladosporium.

Crosses for obtaining $\mathrm{F}_{1}$ hybrids were conducted manually on 2-4 flowers. The crossing was performed on the first 5 flowers of inflorescence, and the other flowers were removed. Castration and pollination were carried out in the phase of a yellow-green flower bud using a pen nib. Pollinated flowers were isolated in a cotton wool. Hybrids and parental lines were tested in unheated glass greenhouses in spring-summer rotations of 1997-2006. Seedlings were planted in the greenhouses on May 10-16. Nutrition area per plant was $60 \mathrm{~cm} \times 40 \mathrm{~cm}$. Parental forms and hybrids were tested simultaneously in 3-fold repetition at random placement.

Major quantitative characters of early and total productivity were recorded during a growing season: fruit weight and number per plant, average fruit weight in the first month of harvesting (early harvest) and in a total harvest.

Statistical processing of the experimental data was performed by the analysis of variance under hierarchical model (11).

Results. The hybrid Start $F_{1}$ was the result of two cycles of periodic selection on the two forms of greenhouse tomato - 24-E and 12-B that had been pre-tested in topcrosses and diallel crosses for combining ability and other genetic properties. It has been shown that both these forms have high combining ability for fruit weight and number per plant in early and total harvest, 12-B also had a complementary non-allelic interaction of major productivity characters. The best plants were selected considering a complex of traits (average fruit weight, weight and number of fruits per plant in early and total harvest); these plants were the matherial for the 2year creation of new lines. Simultaneously were carried out reciprocal crosses: all maternal lines $24-\mathrm{E}$ were crossed with one paternal form 12-B, and all paternal plants 12-B - with one maternal 24-E. Hybrids were tested in the greenhouses in 3 replicates.

The analysis of variance showed significant differences between hybrids for yield (difference in total harvest - over $30 \%$ ). The best hybrids exceeded the source $\mathrm{F}_{1}$ hybrid $24-\mathrm{E} \times 12-\mathrm{B}$ by $17 \%$. Parental lines of these best hybrids were included in crosses of 
the second cycle performed according to the abovementioned scheme. For this purpose, among the parental lines of best hybrid combinations had been selected three maternal lines $(1008,19 / 29,19 / 30)$ and two paternal lines $(19 / 31$ and 19/32) that were crossed to obtain six hybrids $F_{1}$. All the five lines and six hybrids had been planted in a greenhouse, and two plants were selected from each parental line of best hybrids to be the progenitors for the new lines: six maternal and four paternal ones. Crosses between these plants were aimed at obtaining improved hybrids that were tested for 2 years (Table 1). The improved hybrids exceeded the source 24 -E $\times$ $12-\mathrm{B}$ by an average of $4 \%$. However, the difference among these hybrids themselves averaged $27 \%$, and characters of the best hybrids exceeded those of the initial hybrid $24-\mathrm{E} \times 12$-B by $17 \%$. Two of the six hybrids $(19 / 30 \times 19 / 32$ and $19 / 29 \times 19 / 32)$ exhibited stably higher productivity compared with the original hybrid Start in both years of testing. These facts show the efficiency of reciprocal periodic selection in breeding programs of greenhouse tomato.

1. Productivity of best hybrids of tomato Licopersicon esculentum Mill. created on the base of hybrid Start through reciprocal periodic selection, shown by years of observation in conditions of non-heated glass greenhouse (Institute of Genetics and Cytology of the NAS of Belarus, Minsk)

\begin{tabular}{l|c|c|c|c|c|c}
\hline \multirow{2}{*}{ Cross scheme } & \multicolumn{2}{|c|}{2001} & \multicolumn{2}{c|}{2002} & \multicolumn{2}{c}{ Average } \\
\cline { 2 - 7 } & $\mathrm{kg} / \mathrm{plant}$ & to initial, $\%$ & $\mathrm{~kg} /$ plant & to initial, $\%$ & $\mathrm{~kg} /$ plant & to initial, $\%$ \\
\hline $1008 \times 19 / 31$ & 3.05 & 91.0 & 2.74 & 93.8 & 2.90 & 92.4 \\
$1008 \times 19 / 32$ & 3.16 & 94.3 & 2.50 & 85.6 & 2.83 & 90.1 \\
$19 / 29 \times 19 / 31$ & 3.42 & 102.1 & $3.16^{*}$ & 108.2 & 3.29 & 104.8 \\
$19 / 29 \times 19 / 32$ & $3.65^{*}$ & 109.1 & $3.13^{*}$ & 107.2 & 3.39 & 108.0 \\
$19 / 30 \times 19 / 31$ & $4.03^{*}$ & 120.3 & 3.00 & 102.7 & 3.52 & 112.1 \\
$19 / 30 \times 19 / 32$ & $4.01^{*}$ & 119.7 & $3.35^{*}$ & 114.7 & 3.68 & 117.2 \\
Mean & 3.55 & 106.0 & 2.98 & 102.1 & 3.27 & 104.1 \\
$24-\mathrm{E} \times 12-\mathrm{B}$ & 3.35 & & 2.92 & & & \\
(source hybrid) & $(\mathrm{D}=0.29)$ & 100.0 & $(\mathrm{D}=0.21)$ & 100.0 & 3.14 & 100.0 \\
* Reliably exceeds $24-\mathrm{E} \times 12-\mathrm{B}$ at $\mathrm{P}=0.05$. & & & &
\end{tabular}

Firstly it was expected that paternal form 12-B will pass its immunity to TMV and Cladosporium to its hybrids $\mathrm{F}_{1}$. However, long-term cultivation revealed splitting of this trait. That's why selection of the lines descending from 12-B was conducted with main attention to this property rather than productivity.

Such experimental plan allowed estimating genotypic variation within maternal and paternal forms after two cycles of selection using the analysis of variance under hierarchical model (Table 2). The first cycle of selection provided a significant influence on genotypic variability between the lines coming from 24-E (at $\mathrm{P}=0.05$ ) only for fruit number per plant and average fruit weight in early harvest. After the second cycle of selection there was a highly reliable differences between the lines (at $\mathrm{P}=0.01)$ in fruit weight and number per plant in early and total harvest. For example, after two cycles of selection the line $30_{\mathrm{p} 5}$ exceeded the source line 1008 in fruit weight per plant in early harvest by $8 \%$, and in total harvest - by 10\% (while productivity of lines descending from 24 -E is on average $\approx 2.8 \mathrm{~kg}$ ), in number of fruits per plant - by $7 \%$.

2. Results of the two-way analysis of variance (under hierarchical model) of productivity traits in parental lines of hybrid Start improved by two cycles of periodic selection in conditions of non-heated glass greenhouse (Institute of Genetics and Cytology of the NAS of Belarus, Minsk)

\begin{tabular}{|c|c|c|c|c|c|c|c|}
\hline \multirow{4}{*}{ Cause of variation } & \multirow{4}{*}{$\begin{array}{l}\text { Number } \\
\text { of degrees } \\
\text { of free- } \\
\text { dom }\end{array}$} & \multicolumn{6}{|c|}{$\begin{array}{l}\text { Average squares in a ratio to the character in individual observation and } \\
\text { in experiment }\end{array}$} \\
\hline & & \multicolumn{3}{|c|}{ early harvest } & \multicolumn{3}{|c|}{ total harvest } \\
\hline & & \multicolumn{2}{|c|}{ per plant } & \multirow{2}{*}{$\begin{array}{l}\text { average fruit } \\
\text { weight, g }\end{array}$} & \multicolumn{2}{|c|}{ per plant } & \multirow{2}{*}{$\begin{array}{l}\text { average fruit } \\
\text { weight, } g\end{array}$} \\
\hline & & $\begin{array}{l}\text { fruit weight, } \\
\mathrm{kg}\end{array}$ & $\begin{array}{l}\text { fruit number, } \\
\text { pcs }\end{array}$ & & $\begin{array}{l}\text { fruit weight, } \\
\mathrm{kg}\end{array}$ & $\begin{array}{l}\text { fruit number, } \\
\text { pcs }\end{array}$ & \\
\hline \multicolumn{8}{|c|}{ Lines derived from 24-E } \\
\hline Total & 59 & $\approx 0.11^{* *}$ & $\approx 22.50^{* *}$ & $\approx 514.33^{*}$ & $\approx 0.25^{* *}$ & $\approx 53.24 * *$ & $\approx 150.55$ \\
\hline I cycle of selection & 2 & 0.98 & $361.27 *$ & $5243.58^{*}$ & 1.21 & 519.47 & 1091.07 \\
\hline II cycle of selection & 3 & $0.57 * *$ & $47.27 * *$ & 245.39 & $1.51 * *$ & $134.60 * *$ & 136.52 \\
\hline Random deviations & 54 & 0.04 & 2.30 & 264.42 & 0.11 & 22.82 & 99.08 \\
\hline Amount of effects, \%: & & & & & & & \\
\hline I cycle of selection & & 18 & $70^{*}$ & $49 *$ & 0 & 36 & 32 \\
\hline II cycle of selection & & $46^{* *}$ & $20 * *$ & 0 & $57 * *$ & $21^{* *}$ & 2 \\
\hline \multicolumn{8}{|c|}{ Lines derived from 12-B } \\
\hline Total & 59 & $\approx 0.05^{* *}$ & $\approx 23.88^{* *}$ & $\approx 329.30^{* *}$ & $\approx 0.24 * *$ & $\approx 82.14^{* *}$ & $\approx 93.38^{* *}$ \\
\hline I cycle of selection & 2 & 0.17 & $398.47^{*}$ & $5395.80^{*}$ & 0.07 & 747.80 & $1333.23 * *$ \\
\hline II cycle of selection & 3 & $0.17 * *$ & $18.20 * *$ & $249.46^{* *}$ & $0.76^{* *}$ & $235.53 * *$ & 4.20 \\
\hline Random deviations & 54 & 0.04 & 3.39 & 52.26 & 0.18 & 36.64 & 29.18 \\
\hline Amount of effects, \%: & & & & & & & \\
\hline I cycle of selection & & 0 & $80 * *$ & $78^{* *}$ & 0 & 31 & $69^{* *}$ \\
\hline $\begin{array}{l}\text { II cycle of selection } \\
* \mathrm{P}<0.05 ; * * \mathrm{P}<0.01\end{array}$ & & $26 * *$ & $6^{*}$ & $6^{*}$ & $24^{* *}$ & $24 * *$ & 0 \\
\hline
\end{tabular}

Lines selected from $12-\mathrm{B}$ were less productive (on the average $\approx 2.1 \mathrm{~kg}$ per plant). After two cycles of selection significant genotypic differences were observed in all analyzed characters except average fruit weight in total harvest. However, the improved lines $31_{\mathrm{p} 7}$ and $32_{\mathrm{p} 8}$ reliably differed from of the initial line $12-\mathrm{B}$ in productivity by only $5 \%$ though they were resistant to Cladosporium until October, i.e. almost though the whole growing season in contrast to the line 12-B whose plants were partially damaged by these pathogens already at early harvest. For this reason 12-B wasn't used in subsequent crosses.

Hybrids $F_{1}$ Start derived from the lines improved by two cycles of selection were tested in following three years. Results of testing the best combinations (Fig.) confirmed that all $\mathrm{F}_{1}$ hybrids exceeded the best parntal line in total productivity. On the average, true heterosis varied by years of testing from 6.0 to $12.5 \%$, with only exceptions - hybrids $8_{\mathrm{p} 2} \times 31_{\mathrm{p} 4}$ and $8_{\mathrm{p} 2} \times 32_{\mathrm{p} 8}$ that in 2006 manifested an intermediate inheritance of the trait "fruit weight per plant" in both early and total harvest. Among the six tested combinations there was an outstanding hybrid $30_{\mathrm{p} 5} \times 32_{\mathrm{p} 8}$ exceeding the best parental line by $8-46 \%$ (depending on year of testing). Moreover, in contrast to the initial hybrid $24-\mathrm{E} \times 12-\mathrm{B}$, this resulting hybrid developed $10 \%$ higher yield of fruits $\left(\right.$ per $\left.1 \mathrm{~m}^{2}\right)$ and immunity to TMV and Cladosporium until the end of vegetation. 
Loss of resistance to Cladosporium in 12-B necessitated other sources of immunity to diseases, and the form 21-17 was selected upon the results of diallel cross analysis of 12 samples of different eco-geographical origin. All the samples were tested for several quantitative and qualitative traits. The form 21-17 showed high combining ability for components of early and total productivity, as well as resistance to TMV and Cladosporium.

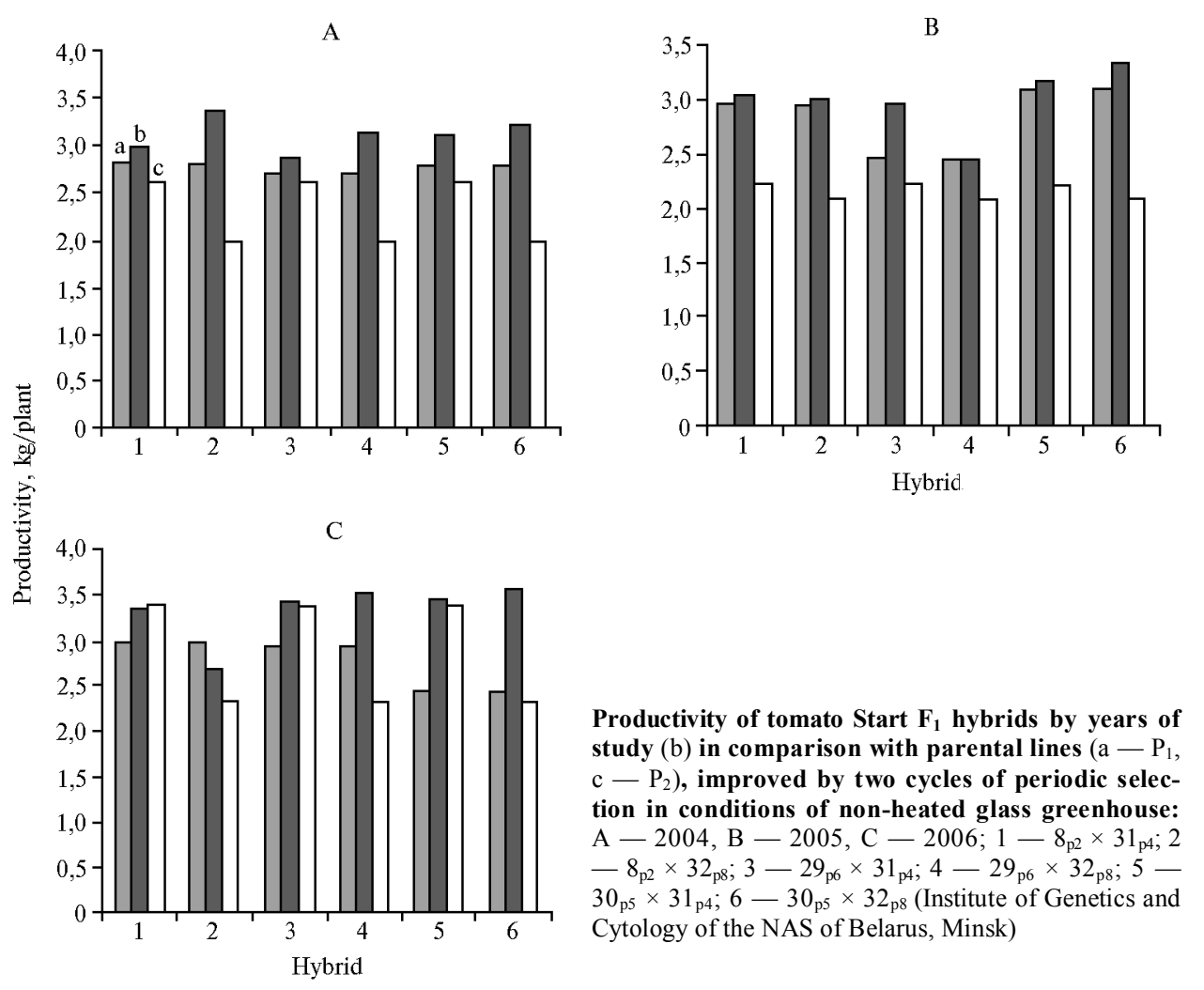

Along with it, one of the best diallel $F_{1}$ hybrids 24-E $\times 21-17$ called Nadezhda for several years stably manifested a heterosis $(35 \%)$ in fruit weight and number of fruits per plant. On maternal and paternal lines of best plants the cross $24-\mathrm{E} \times 21-17$ it was also conducted intra- and inter - population selection according to the abovementioned scheme, and after two cycles of selection there were derived two lines $17_{\mathrm{p} 1}$ and $17_{\mathrm{p} 3}$. They were crossed with the best lines from $24-\mathrm{E}$, which resulted in hybrids $\mathrm{F}_{1}$ exceeding the source hybrid $24-\mathrm{E} \times 21-17$ in productivity on the average by $5 \%$. The improved hybrid Nadezhda $1\left(29_{\mathrm{p} 2} \times 17_{\mathrm{p} 1}\right)$ manifested productivity $6 \%$ higher than that of the initial hybrid as well as immunity to TMV and Cladosporium.

Thus, this research has proved the efficiency of periodic selection with minimal inbreeding and cyclic hybridization performed in order to increase the frequency of desirable genes for productivity traits and resistance to diseases; the used schemes of selection can be proposed for improving parental lines and enhancing the hybrid power of greenhouse tomato $F_{1}$ hybrids.

\section{REFERENCES}

1. Wehner T.C. Heterosis in vegetable crops. The genetics and exploitation of heterosis in crops. American Society of Agronomy Inc., Madison WI, 1999: $387-398$. 2. Melchinger A.E., Geiger H.H., Utz H.F., Schnell F.G. Effect of recombination in the parent populations on the means and combining ability variances in hybrid populations of maize (Zea mays L.) Theor. Appl. Genet., 2003, 106: 332-340.

3. Lori L.H., Lamkey K.R. Absence of epistasis for grain yield in elite maize hybrids. Crop Sci., 2003, 43: 46-56.

4. Tarutina L.A., Kavtsevich V.N., Poskannaya S.I., Khotyleva L.V., Kapusta I.B. Doklady NAN Belarusi, 2000, 44(1): 72-75.

5. Khotyleva L.V., Tarutina L.A., Kapusta I.B., Mishin L.A. Sbornik nauchnukh trudov «Ekologicheskie osnovy plodoovoshchevodstva» [Compilation of Sci.

Works «Ecological Fundamentals of Plant Growing»]. Gorki, 2005: 143-146.

6. Kaminskaya L.N. Rekurrentnaya selektsiya [Recurrent Breeding]. Minsk, 1985.

7. Kil'chevskii A.V., Khotyleva L.V. Genotip i sreda v selektsii rastenii[Genotype and Environment]. Minsk, 1989: $172-175$.

8. Virmani S.S. Heterosis and hybrid rice breeding. Berlin, 1994.

9. Spreg Dzh.F. Geterozis u kukuruzy: teoriya i praktika. Geterozis [Heterosis in Maize: Theory and Practice]. Moscow, 1987: 71-97.

10. Kil'chevskii A.V. Effektivnost' pervogo tsikla periodicheskogo otbora u tomatov. Avtoreferat kandidatskoi dissertatsii [Effectiveness of the First Cycle of Periodic Selection in Tomatoes. PhD Thesis]. Minsk, 1982.

11. Rokitskii P.F. Vvedenie v statisticheskuyu genetiku [An Introduction to Statistical Genetics]. Minsk, 1978: $292-301$. 